\title{
A CASE OF CONCUSSION OF THE SPINAL CORD, RESULTANT ON A GRAZE BY A LIVE SHELL : WITH ESPECIAL REFERENCE TO THE PHENOMENON OF 'HETER ESTHESIA'.
}

\section{By T. GRAHAM BROWN, MaNchester.}

THE following case presents points of interest apart from the fact that it is almost impossible to conceive a closer contact with a live shell without death.

Lieut. V., R.A.F., age 22, was acting as observer in an aeroplane which came back over the enemy's lines on April 6, 1918, after a reconnaissance. It was flying at about 8000 feet, and he was facing the tail of the machine, when he suddenly felt an "almighty crash" -an " enormous blow, like when he was wounded before, but much worse". Almost simultaneously, but actually a little later, he heard an explosion. He fell under his seat and found that he could not shut his mouth. He was badly winded, and "fought for breath and tried to think what had happened". At first he concluded from his difficulty in breathing, and from a difficulty in closing his mouth, that he was hit in the face. As his breath came back to him he began to doubt whether he was hit in the face after all. There was a general pain all over him which he could not locate. He next tried to touch his face with his hands, to feel for evidence of a wound, and at once found that his hands were limp and that he could not use his arms. With great difficulty he managed to get his gloves off and was able to raise his left hand to his face. He now decided that his arms were hit. There was a sensation in his hands "as if they were getting back feeling after being frost-bitten", and he thought they must have been frost-bitten shortly before, when he had to take off his gloves to handle the gun. But on looking at his hands he could see no sign of this. About this time the pilot evidently suspected that something was wrong, for he telephoned, "Are you hit, sir ?" On landing, after being lifted out of his seat, he was at once placed on a stretcher, and taken to a casualty clearing station. He did not try to walk, but thinks that he could have done so.

At the Clearing Station it was found that his leather coat was marked across the shoulders by the driving-band of an anti-aircraft shell. A photograph of this coat was made, and it is reproduced 
in Fig. 1. It will be observed that the marks shown are unmistakably those of a shell, and almost certainly produced by the grooved copper driving-band. It seems to me that the shell must have been travelling from the patient's left to right. The horizontal direction of the mark is somewhat unexpected. It is explained by the fact that he was leaning over the side of the machine at the time.

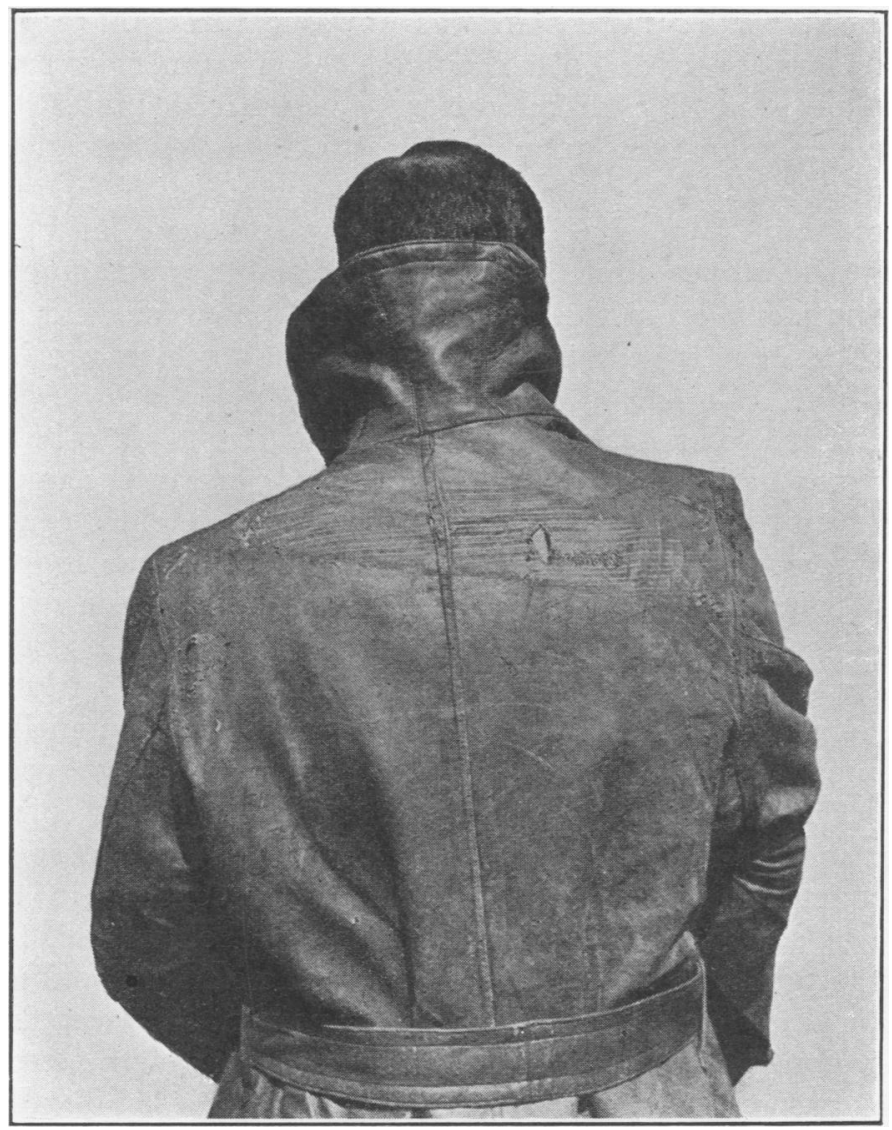

FIG. 1.-Photograph of aviator's leather coat, showing marks made by driving-band of anti-aircraft shell.

The hole in the leather lies directly over the internal border of the right scapula. It is worthy of remark that, until this was found, he had no idea that he had been hit on the back.

He was treated for two days at the clearing station, but is rather hazy about what happened to him there. Bruises on the back were treated in the ordinary way, and it was decided that no bones were broken. He was then transferred to the neurological department of the British Salonika Force, and admitted there on April 8. 
On Admission.-It was found that the patient had great difficulty in moving his arms, the paresis being greater in the case of the right upper limb than in that of the left. His shoulders were badly bruised, especially over the upper halves of the two scapulæ. Across this region, and accurately corresponding with the marks on his coat, were a number of long parallel wheals. These were most marked over the internal borders and spines of the scapulæ-and more on the right than on the left side. The skin was nowhere broken. There was a diffuse discoloration over both shoulders, as if from a severe bruise; and later on a similar discoloration was noticed under the right clavicle. The following facts, amongst others less essential, were observed at this time.

He complained of pain in the shoulder and neck, and of painful tingling in the upper limbs. Apart from slight nystagmoid movements of the eyeballs, in the extreme lateral positions, and a marked tremor of the protruded tongue, the cranial nerves were normal. The pupils were dilated.

With regard to sensation, there was little abnormal to be detected. Slight hyperæsthesia and hyperalgesia were present in the upper limbs, particularly in the areas of distribution of the eighth cervical and first and second thoracic dorsal spinal roots. This was more marked in the right than in the left limb. No area of anæsthesia or analgesia could be detected. The kinæsthetic sensations were apparently normal. There was no astereognosis. Compass tests were fairly accurate. Localization could not be tested. Lower limbs were apparently normal.

The most interesting sensory disturbance was the presence of 'heteræsthesia'. This is a phenomenon which was first observed in this department in cases of partial compression of the spinal cord, cerebral concussion, and shell concussion. It consists in this, that if a constant stimulus (such as that given by the scratch of a pin or by a mild faradic current) is moved across the skin, the subject states that it feels stronger or weaker at certain points. These points, when carefully mapped out, are found to lie on lines which correspond to the boundaries of the segmental or radicular areas of distribution of the afferent nerve fibres. In this case the phenomenon was very well marked in the upper limbs-so that nearly all the boundary lines could be traced, even on the hand, which is relatively blunted in this condition as a rule. 'Heteræsthesia' was not well marked above the fifth cervical segment, although there was a somewhat vague indication of the outline of the fourth cervical area. It was, however, clear on the thorax, abdomen, and lower limbs. The phenomenon was tested by two independent and rather sceptical observers, who found the lines of change to correspond very nearly with those mapped by the writer. 
The abdominal reflexes were present; the cremasterics were brisk; the plantar responses were brisk flexion; and all these responses were equal on the two sides of the body. The supinator jerks and the biceps jerks were absent in the upper limbs. The triceps jerks were present and equal on the two sides. The knee-jerks were equal on the two sides, and they were brisk. So, too, were the anklejerks. There was slight ankle-clonus.

Motor power was defective in the upper limbs. In the right, slight movement was present at all joints. There was great paresis, but no absolute paralysis. In the left upper limb the paresis was less than in the right, but it was well marked. The left hand-grip was stronger than the right. Patient was able with difficulty to raise his right hand to his face, and could raise his left hand much more easily. Motor power was apparently normal in the lower limbs.

There was marked inco-ordination in the movements of the upper limbs. So much was this the case that he could not feed himself. In the 'finger-nose' test his movements were wildly inco-ordinate. He stabbed his finger all over his face, and even, in the case of his right hand, missed his face altogether. This inco-ordination was present when he did the test with open eyes. It was most marked on the right side.

When lumbar puncture was performed, the cerebrospinal fluid was found to be under marked pressure. There was no increase in the globulin content, and a cell count showed six cells per c.mm.

The bruises were treated in the ordinary manner, and he was made to feed himself, at first with help, later without it. Improvement was rapid.

Progress.-One week later, on April 15, the 'heteræsthesia' was still marked in both upper limbs as high as the fourth cervical root area. It was now slightly marked on the abdomen, and absent in the lower limbs. There was marked hyperæsthesia of both upper limbs in the fourth or fifth cervical to fourth thoracic dorsal root areas. He complained of numbness in these areas, but there was no kinæsthetic disturbance.

In the right upper limb the reflexes were as before, but in the left the biceps jerk was present and a slight supinator jerk could be obtained. The motor power of the left upper limb was now apparently normal. In the case of the right upper limb the hand-grasp was weak, but movement was weaker at the shoulder than elsewhere. The movements of the wrist and fingers were weak, and flexion of the elbow was weak, although extension was fairly strong. The movements of the left upper limb, and both lower limbs, now showed no inco-ordination; but there was still a certain amount of inco-ordination in the movements of the right upper limbs, for 
instance in the 'finger-nose' test. This inco-ordination was, however, much less than before. There was much stiffness in the right shoulder, and pain when it was moved. Massage was now commenced.

The steady improvement was maintained, and a fortnight later, on April 29, the movements of the right upper limb were much greater in extent and strength. Six days later he complained of the numb feeling in the right upper limb only. This was now confined to the areas of distribution of the seventh cervical to third dorsal root areas. There were hyperæsthesia and hyperalgesia in these areas, also now on the right side only. There was no sensory loss of any sort. 'Heteræesthesia' 'was present in the right upper limb, less well defined in left, and absent elsewhere. Motor power was now good. All individual movements of the right upper limb could be performed fairly well. He could deal a pack of cards with his right hand. His right hand-grasp was still weaker than his left. There was little, if any, inco-ordination in the movements of the right upper limb. Pointing tests were done fairly accurately with either hand. There was a fine tremor of his outstretched fingers. His gait, which had been rather uncertain fourteen days before, was now normal. No Rombergism was noted.

On May 12 he was evacuated, the movements of the right upper limb having still further improved in strength.

Remarks.-This case may with confidence be described as one of concussion of the lower cervical and upper thoracic spinal cord, brought about by the direct hit (or graze) of a live shell. It is of interest as an instance of a very narrow escape indeed; and it is well-nigh impossible to conceive that any man could have been in actual contact with a shell in its flight and yet escape, not only with his life, but with such comparatively slight injuries, and actually with an unbroken skin. Perhaps other similar cases have been reported, but no parallel instance has met my eye.

But there is also a more scientific interest in the association of the phenomenon of 'heteræsthesia' with concussion of the spinal cord. It has already been stated above that this phenomenon has previously been observed in cases of general concussion of the nervous system (shell concussion), of cerebral concussion (with fracture of the base of the skull), and of partial compression of the spinal cord.

In the first two of these three classes there may be no other sensory disturbance. In the last the analogous phenomenon occurred below the level of injury of the cord, and only upon one side of the body. It is not difficult to frame an hypothesis which will cover these different cases. The state of 'excitability' of different parts of 
the nervous system is known to vary under different conditions. The primitive segments of the spinal cord may be considered, in a sense, as different individual parts of the nervous system. Complex co-ordinated acts which involve many different spinal segments might be rendered inefficient if the states of 'excitability' of these different spinal segments varied more or less fortuitously amongst themselves. As this inefficiency does not normally occur, it may be argued that a function of the co-ordinating mechanisms which integrate the different parts of the nervous system is the control of states of excitability, so that different segments are kept properly in tune. As the great co-ordinating mechanisms have their chief centres towards the head end of the animal, these co-ordinating paths - whether propriospinal or passing from cerebral or mid-brain centres to other parts of the nervous system-are most probably descending. A concussion may for a time throw this mechanism out of gear, or a lesion (as in partial compression of the spinal cord) may interrupt the descending tracts. In either condition the lower segments may pass out of control (or out of full control) of the co-ordinating centre, and may assume different states of 'excitability' more or less independently. In these circumstances the values of equal stimuli may be different when the in-going nerve-impulses which they engender impinge upon different segments. Hence the phenomenon of 'heteræsthesia'.

The case described above is of further interest inasmuch as the 'heteræsthesia' was at first widespread below the parts primarily affected, as if the long descending paths (on our hypothesis) had been affected. Later on, this widespread distribution disappeared and the phenomenon was confined to a comparatively small number of spinal segments. It looks as if the condition was then due to more or less local factors, and not to a concussion of the chief centres*; in other words, that it was due to a local disturbance of the spinal segments in the lower cervical and upper thoracic regions. This disturbance may have been a disturbance of the central nerve endings, in this region, of the descending paths from the chief centres, or of the mechanisms upon which these paths acted, or of the shorter propriospinal paths.

It may perhaps be inferred that the phenomenon of 'heterrsthesia' may result not only from a concussion of the higher centres, or an interruption of their descending paths, but also from a local concussion or disturbance of the mechanisms in the spinal cord itself.

* The breathlessness and the difficulty in closing his mouth which the patient experienced immediately after the blow of the shell both point to a concussion of nerve centres higher than those in the cervical spinal cord. 